\title{
Analysis of the Social Factors Affecting the Fading of the Japanese Vocabulary in Taiwanese Hokkien Among College Students in Taichung Area
}

\author{
Jungmin $\mathrm{Li}^{1}$ and JungChih Tsai ${ }^{1, *}$ \\ ${ }^{1}$ School of Humanities, Minjiang University, Fuzhou, Fujian 350108, China \\ *Corresponding author. Email: jungchih99@qq.com
}

\begin{abstract}
Taiwanese Hokkien has been profoundly influenced by Japanese and Mandarin successively. The official language of Taiwan today is Mandarin, as a consequence, the former official language, Japanese, is rapidly disappearing in Taiwanese Hokkien. Therefore, this research will focus on the Japanese vocabulary in Taiwanese Hokkien used by college students in Taichung area. On the one hand, it will share the observation on the decline of Japanese vocabulary in Taiwanese Hokkien; on the other hand, it will discuss the significant impact of the social change on the fading rate of these Japanese words. This research will reveal the language change caused by the differences in gender, expertise, performance, and learning environment of college students. In addition, these students, aged from 18 to 22, are brought up immersed in Mandarin as the official language. Through this research, we can also witness the achievement of the Mandarin-mother tongue education as of today.
\end{abstract}

Keywords: Sociolinguistics, Taiwanese Hokkien, Japanese vocabulary, language change, statistical tests

\section{INTRODUCTION}

In Modern history, Taiwan has been under the rule of Japanese and then the governance of Republic of China. Therefore, Taiwanese Hokkien has also experienced the successive influences of Japanese and Mandarin. Japanese vocabulary enters Taiwanese Hokkien in two forms: "borrowed sounds" and "loan words." Then, certain Japanese words become part of Taiwanese Hokkien by the means of "phonological adjustment", "lexical reorganization" and "division of vocabulary". However, because Taiwan's official language has now changed to Mandarin, Japanese as the former official language is rapidly disappearing from Taiwanese Hokkien.

This research will focus on the fading of Japanese vocabulary in Taiwanese Hokkien, with university students in Taichung as the research object. After William Labov pointed out that language variations are affected by social factors, scholars begin more or less to consider social factors when conducting language surveys or language research. However, in Taiwan's research, most scholars are only concerned with the social variable of age, and pay less attention to other social variables that affect language changes. Therefore, this paper's focus will be placed on other social variables.

\section{RESEARCH METHODS}

This survey was conducted in December 2009. The main Japanese vocabulary words surveyed were 12 "borrowed sound" words and 4 "loanwords". In addition, the word "screw" used in contrast to "screwdriver." These 12 "borrowed sound" vocabulary and 4 "loanwords" are vocabulary that is not spoken in the traditional Taiwanese Hokkien. Therefore, as far as Taiwanese youth is concerned, these 16 Japanese words can be considered as the traditional Taiwanese Hokkien vocabulary.

(these 16 vocabulary are: 12 "borrowed sound" words: steering wheel, rear mirror, bumper, clutch, gearbox , Engine, shock absorber, reversing, car battery, screwdriver, mobile phone battery, lighter, and 4 "loanwords:" machine, business trip, order, and number.)

The survey subjects were the following nine universities in the Taichung area:

1. Chung Shan Medical University, (CSMU) 2. China Medical University, (CMU) 3. Central Taiwan University of Science and Technology, (CTUST) 4. National Taichung University of Science and Technology, (NTCUST) 5. National Chin-Yi University of Technology, (NCUT) 6. Overseas Chinese University, (O.C.U) 7. Feng Chia University, (FCU) 8. National Taichung University of 
Education, (NTCU) 9. National Chung Hsing University, $(\mathrm{NCHU})$

From each university, we surveyed 20 males and 20 females. A total of 360 people had been investigated.

The four control variables observed were: 1, university ranking, 2 , university category, 3 , department, 4 , gender.

Under these four types of variables, mean and variance were used for cross-comparison. We then apply the most appropriate verification method according to the nature and quantity of the samples, and then use Minitab to make a box plot data distribution chart to facilitate data analysis.(For formulas, please refer to Jungmin Li, 2015)

At this stage, we will use the variance and the mean for data analysis. Firstly, we will discuss whether the variance of each group of cut data is the same, which means the degree of concentration of the data is consistent. Whether the data is consistent or not will affect the subsequent mean analysis. After confirming the variance, we will further analyze the mean. The more increase in the mean, the better the Japanese will be preserved.

\section{DETAILED PERFORMANCE ANALYSIS}

The control variables we observed in this research are divided into four primary categories and some minor categories.

1. University Ranking: 1-1 High, 1-2 Medium, 1-3 Low.

2. University Type: 2-1 Medical University, 2-2 University of science and technology, 2-3 Comprehensive University.

3. Major: 3-1 Liberal arts major, 3-2 Science major, 3-3Health and medicine majors.

4. Gender: 4-1 Male, 4-2 Female.

According to our grouping method, there should be 54 categories. However, there are some NA values in some variables, we would only get 30 categories in this research.

(1) Variance $\sigma^{2}$, Variance is the statistical dispersion between each sample and the Mean.

By using Minitab, we can see the variance difference for each variable in a different situation. See Fig. 1.

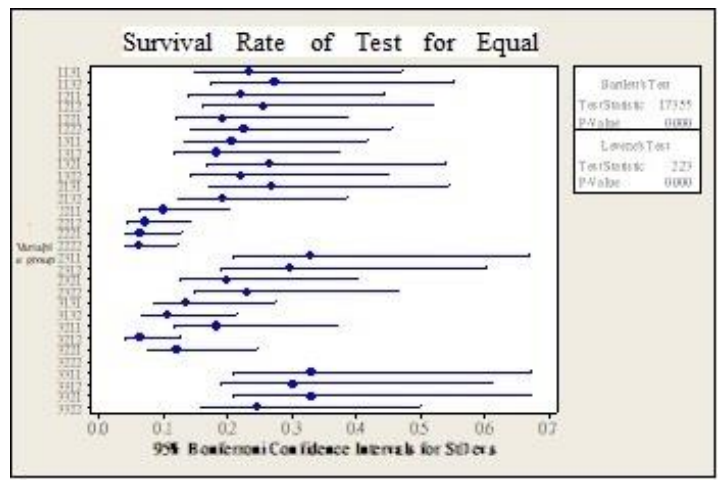

Figure 1. Survival Rates of Japanese Vocabulary of Equal Variances

In Fig. 1, we can see from the top-right corner that the P-value of Bartlett's Test and the P-value of Levene's Test are all 0.000 , which means the variance is different in each group. P-value is the smallest level of significance to reject the null hypothesis. It means the variance is different.

(2) Mean is the average of all the numbers in the sample.

The third column in Fig. 2 is the mean, and the fourth column is the Standard Deviation. The square of the standard deviation is the variance.

The higher the average, the better the way we keep the Japanese usage.

We can see the data of male students major in Liberal art from Feng Chia University, the IQR lies between 0.05 to 0.75 ; the average is 0.35 ; the median is 0.25 which is the highest in the 30 categories. So, male students major in liberal art from Feng Chia University is the best at keeping Japanese usage compared to other college students in Taichung. But the reason that male students major in Liberal art from Feng Chia University perform better than other students is that the ratio they could answer the Japanese usage question is much higher. The average is 0.35 which is the highest of all the respondents. It would be worthwhile for us to do some further research to understand the reason.

The Figure below is using Minitab to create Boxplot with groups. 


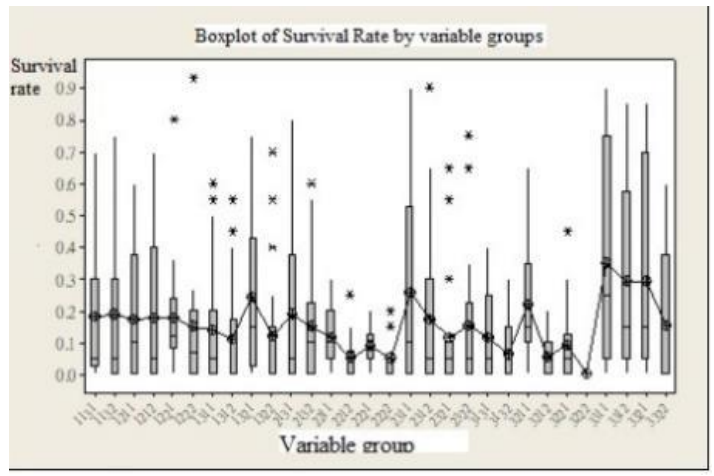

Figure 2. Survival rates of Japanese vocabulary in 30 variable groups

We can see, there is a $\bigoplus$ sign in each group and it shows the value of the mean. The larger the IQR (q3-q1), the more scattered our data is. $\mathrm{q} 2$ is the median. Therefore, we can see when the distance between mean and median is large, the extreme value may be extremely large or extremely small. We can check if there is any typo or error value that increases the average in our sample.

In the next paragraph, we would do some cross-analysis by controlling the variables to see which variables would have impacts on the Japanese usage in Hokkien for a university student in Taichung.

\section{CROSS ANALYSIS (THE PERFORMANCE OF EACH OF THE NINE INSTITUTIONS)}

Using the method in Section 3, we conduct a cross-comparison analysis of each control variable:

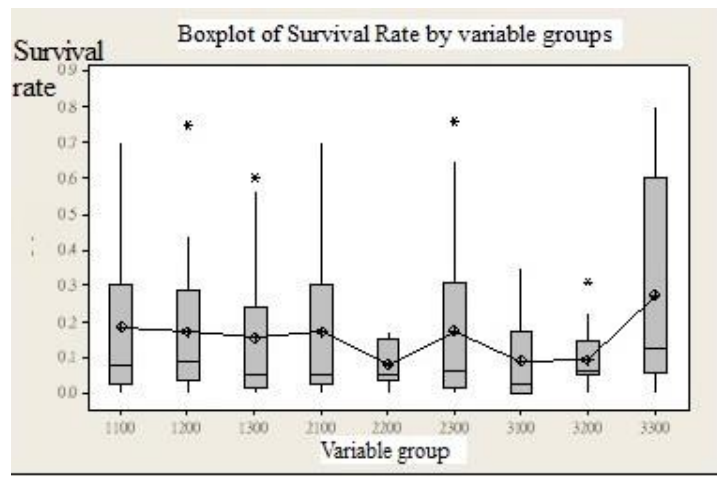

Figure 3. Survival rates of Japanese vocabulary in the nine universities.

The retention rates of Japanese vocabulary in Taiwanese Hokkien are listed in the order as follow (from high to low): Feng Chia University, (FCU) > Chung Shan Medical University, (CSMU) > National Taichung University of Education, (NTCU) > National Taichung University of Science and Technology, (NTCUST) > China Medical University, (CMU) > National Chung Hsing University, (NCHU) > Overseas Chinese University , (O.C.U) > Central Taiwan University of Science and Technology, (CTUST) > National Chin-Yi University of Technology, (NCUT).

However, except for National Taichung University of Science and Technology, the StDev from the top five universities has all exceeded 0.2023 - the Pooled StDev. In other words, in these universities, some words were preserved well, which increased their overall score. Relatively speaking, National Taichung University of Science and Technology remained average in this regard.

Does this outcome have something to do with the composition of university students? We further observe the composition of students in each university:

Table 1. Number of students in nine universities in 2009

\begin{tabular}{|c|c|c|c|c|c|c|}
\hline School code & School name & Day or Evening school & System & Total & Male & Female \\
\hline 0043 & $\begin{array}{l}\text { National Chin-Yi University of } \\
\text { Technology }\end{array}$ & D day & $\begin{array}{l}\text { B four-years } \\
\text { tech. }\end{array}$ & 5,794 & 3,825 & 1,969 \\
\hline 0137 & $\begin{array}{l}\text { National Taichung University } \\
\text { of Science and Technology }\end{array}$ & D day & $\begin{array}{l}\text { B four-years } \\
\text { tech. }\end{array}$ & 4,436 & 1,321 & 3,115 \\
\hline 1007 & Feng Chia University & D day & B Bachelor & 16,211 & 10,568 & 5,643 \\
\hline 1029 & $\begin{array}{l}\text { Chung Shan Medical } \\
\text { University }\end{array}$ & D day & B Bachelor & 6,779 & 2,852 & 3,927 \\
\hline 1035 & China Medical University & D day & B Bachelor & 6,908 & 3,314 & 3,594 \\
\hline 1047 & $\begin{array}{l}\text { Central Taiwan University of } \\
\text { Science and Technology }\end{array}$ & D day & $\begin{array}{l}\text { B four-years } \\
\text { tech. }\end{array}$ & 5,032 & 1,977 & 3,055 \\
\hline
\end{tabular}




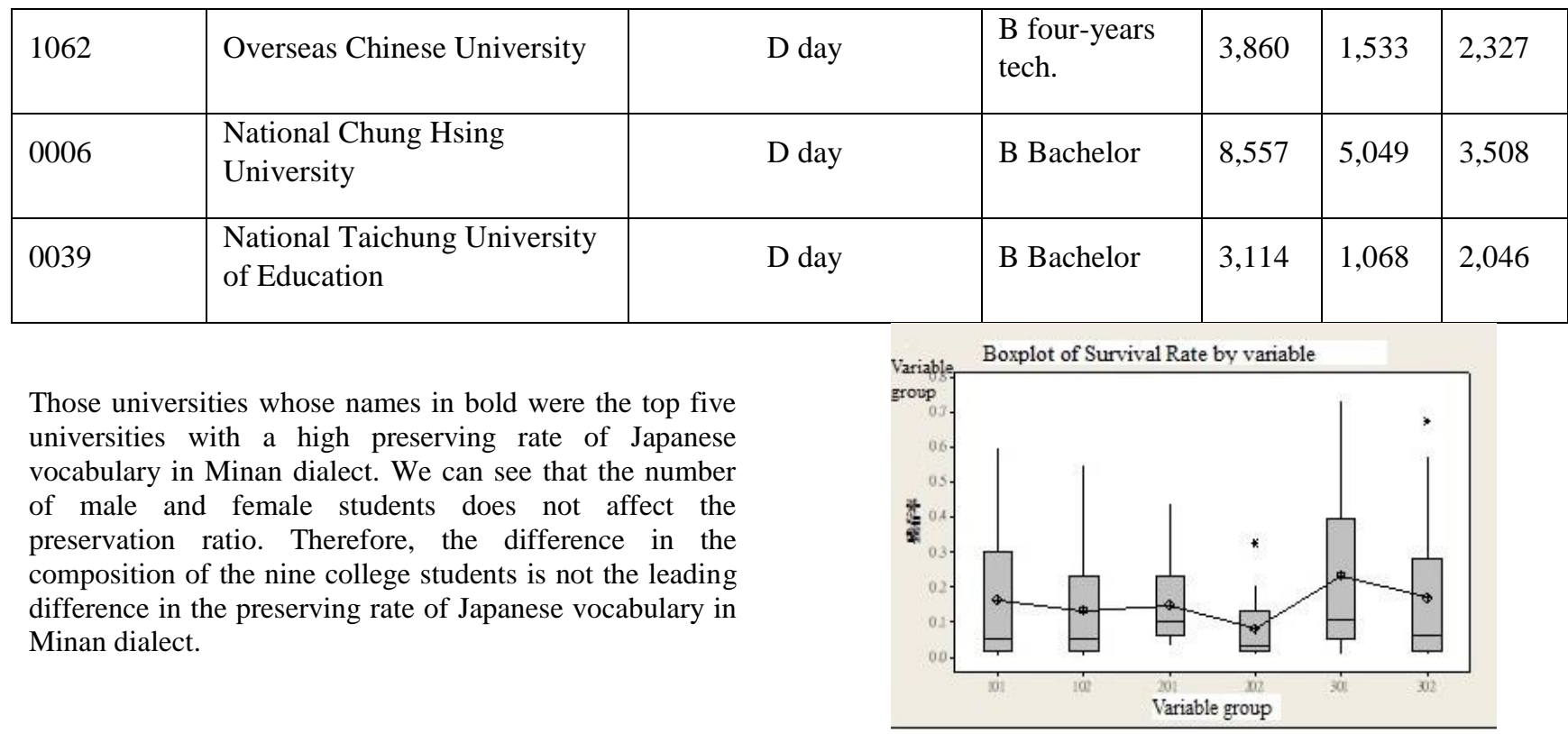

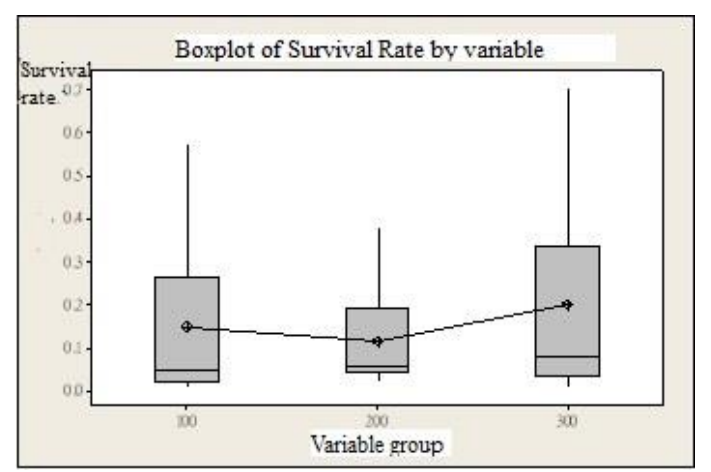

Figure 4. Survival rates of Japanese vocabulary in three types of universities.

The rates of Japanese vocabulary in Hokkien from medical universities, universities of science and technology, and comprehensive universities can be listed as follow (from high to low): comprehensive university > medical university $>$ science and technology university. Among them, the StDev of the comprehensive universities has far passed the 0.1890 of the pool StDev, which means that the comprehensive university has the best lexical preservation, which improves the overall performance. Relatively, the universities of science and technology remained average. Their mean was lower as well. Thus, the preservation rate of Japanese vocabulary is surely the lowest in this group.
Figure 5. Survival rates of Japanese vocabulary in male and female students from three types of universities.

In separate groups of male and female students from medical universities, universities of science and technology, and comprehensive universities, the retention rates of Japanese vocabulary in Hokkien can be listed in the following order (from high to low): male in comprehensive university $>$ female in comprehensive university $>$ male in medical university $>$ male in science and technology university $>$ female in medical university $>$ female in science and technology university.

Among them, the StDev of the three groups from male/ comprehensive university; female/ comprehensive university, and male/ medical university exceeds the 0.1911 of the Pooled StDev.

The group of female students in the University of Science and Technology are both low in their mean and StDev value, which indicate that their retention rate of Hokkien Japanese vocabulary is the lowest.

In addition, due to the performances of male and female students from these three types of universities: medical universities, science and technology universities, and comprehensive universities, the category of university, as a variable, has affected the preservation of Japanese vocabulary in Taiwanese Hokkien to a certain extent. 


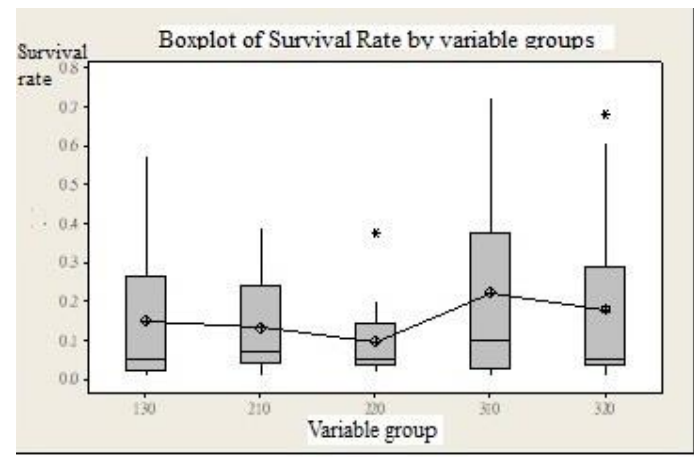

Figure 6. Survival rates of Japanese vocabulary in three majors from three types of universities

Let's look at the respective performances of medical department, science group in comprehensive university, liberal arts group in comprehensive university, science group in university of science and technology, liberal arts group in university of science and technology.

The retention rates of Japanese vocabulary in Taiwanese Hokkien are listed in the following order (from high to low): liberal arts group in comprehensive university > science group in comprehensive university $>$ medical department in medical university > liberal arts group in university of science and technology $>$ science group in university of science and technology.

The mean and StDev valuesof the liberal arts group of comprehensive university and the science group of comprehensive university are relatively high. Both values remain low for the science group in university of science and technology. It shows that the science group of the University of Science and Technology has the worst preservation rate of Japanese vocabulary in Taiwanese Hokkien.

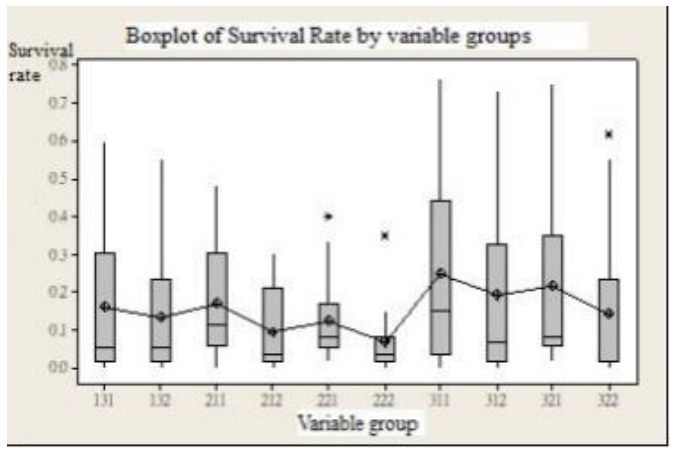

Figure 7. Survival rates of Japanese vocabulary in male and female students of three majors from three types of universities

The retention rate of Japanese vocabulary in Taiwanese Hokkien is listed as follow (from high to low): liberal arts group male /comprehensive university $>$ science group male /comprehensive university > liberal arts group female/ comprehensive university > liberal arts group male /university of science and technology > boys in the liberal arts group/university of science and technology $>$ medical group male/medical university $>$ science group female/ comprehensive university $>$ medical group female/medical university > science group male/university of science and technology > liberal arts group female/ university of science and technology > science group female/ university of science and technology.

University of Science and Technology > women in the science group of the Polytechnic University > women in the medical science group of the University of Medicine and Science > men in the science group of the University of Science and Technology > girls in the liberal arts group of the University of Science and Technology > girls in the science group of the University of Science and Technology.

In this category, the data shows that male college students perform better than female students in terms of Japanese vocabulary retention rate. Nevertheless, it is worth paying special attention to the performance of female students from liberal arts group in the comprehensive university.

They surpass male students both in medical and technological fields. This shows that majoring in liberal arts has an impact on the preservation of Japanese vocabulary. Hence, we will look at the performance from the three different major categories of medicine, science, and liberal arts.

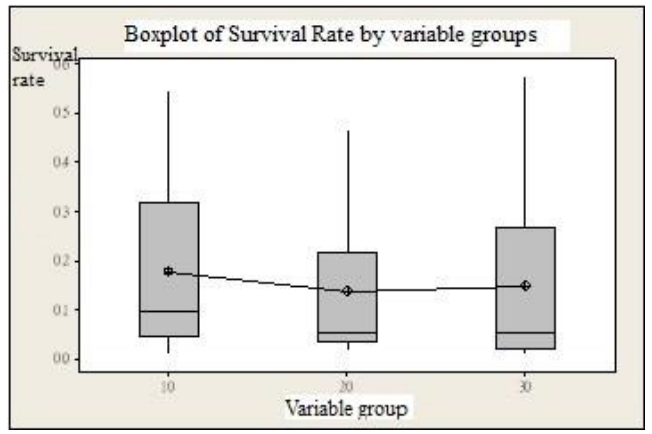

Figure 8. Survival rates of Japanese vocabulary in three majors

For the three different professional categories of medicine, science, and liberal arts, the order of preservation rate of Japanese vocabulary in Taiwanese Hokkien is listed as follow (from high to low): literary group $>$ medical group > science group.

This result shows that different professional categories will have an impact on the preservation of Japanese vocabulary in Taiwanese Hokkien.

Then we shall observe, under different professional categories, whether gender will affect the preservation of Japanese vocabulary in Taiwanese Hokkien. 


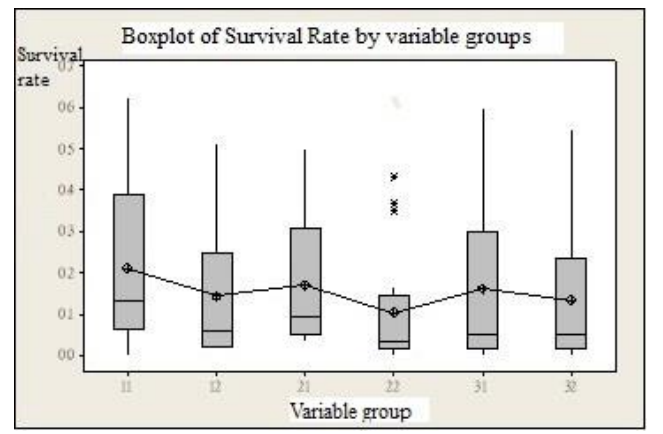

Figure 9. Survival rates of Japanese Vocabulary in male and female students from three majors

In terms of the performance of male and female students from three different majors of medicine, science, and liberal arts, the retention rates of Japanese vocabulary in Taiwanese Hokkien can be listed as follow (from high to low): male in liberal arts group > male in science group > male in medical group > female in liberal arts group > female in medical group $>$ female in science group.

From the above data, we concluded that gender factors have an impact on the retention rate of Japanese vocabulary in Taiwanese Hokkien among college students. Male college students preserve more Japanese vocabulary than female ones.

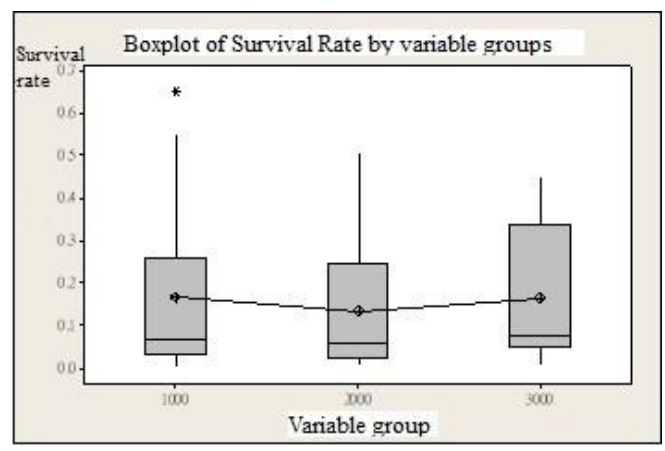

Figure 10. Survival rates of Japanese vocabulary in universities of three different rankings

In terms of the outcome from different ranking universities, the retention rate of Japanese vocabulary in Taiwanese Hokkien is listed as follow (from high to low): the highest $>$ the lowest $>$ the average.

In the variable of university ranking, universities ranked in the top segment have a high retention rate of Japanese vocabulary. However, we should note that in some respects it is actually similar to the lowest universities, and the difference is in the StDev value.

In other words, the universities of the higher ranking performed particularly well in certain Japanese vocabulary, thus raised their mean value. On the other hand, the universities of the lower ranking, among the 17 vocabularies surveyed, maintain an even retention rate of Japanese vocabulary.
Looking at the Boxplot again, we can see an outlier in the universities of the higher ranking. If we replace this outlier, we only compare the IQR value. The higher-ranked universities are mainly distributed between about $0.04 \sim 0.25$, roughly the same as the universities of average ranking. However, the universities of lower ranking mainly concentrated between about 0.05 0.35. In this case, the lower-ranked universities, as a whole, perform better than the higher ones.

Namely, the preservation of Japanese vocabulary in the higher-ranked universities is either excellent; or extremely bad. Accordingly, the variable of university ranking cannot be a determinant of whether the retention rate of Japanese vocabulary is high or low.

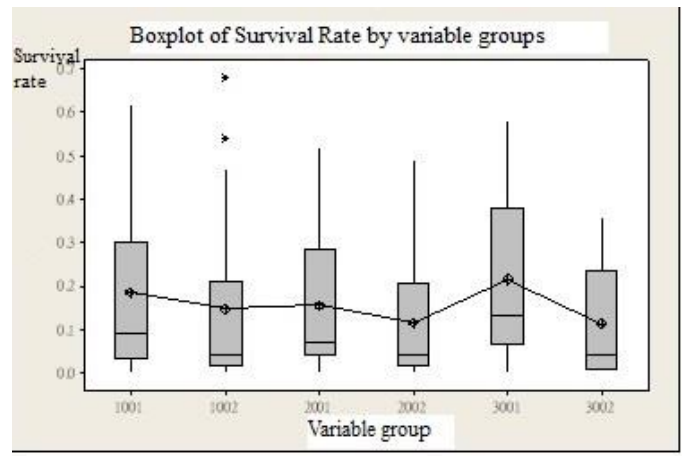

Figure 11. Survival rates of Japanese vocabulary in male and female students from universities of three different rankings

In terms of the performance of male and female students from three different rankings of universities: the highest, the average, and the lowest, the retention rate of Japanese vocabulary in Taiwanese Hokkien is listed as follow (from high to low): male/lower rank > male/higher rank > male/average rank $>$ female/higher rank $>$ female/ average rank $>$ female/lower rank.

The above data shows that the male students from lower-ranked universities preserved Japanese vocabulary better than those from higher-ranked universities. Overall, however, the higher-ranked universities perform better than the lower-ranked ones.

The difference is that the preservation rate of Japanese vocabulary in Taiwanese Hokkien from female students of high-ranked universities remains the highest, while the female students from the low-ranked universities have the lowest ratio. However, there were 2 extreme values for female students from high-ranked universities, which increased their score.

Observing the box plot, we can see that if the female students from high-ranked universities remove these two extreme values and only compare the IQR area, then, we will see, in fact, the female students from universities of all three levels are about the same in their retention rate of Japanese vocabulary in Taiwanese Hokkien. Thus, this 
classification method confirms that the university ranking is not essential for the preserving rate of Japanese vocabulary in Taiwanese Hokkien.

\section{CONCLUSION}

From the cross-analysis and observation in Section Four, we come to the following conclusions:

1. The differences between genders and professional categories are the main factors affecting the retention rate of Japanese vocabulary in Taiwanese Hokkien.

2. The types of university also affect the retention rate of Japanese vocabulary in Taiwanese Hokkien to a certain degree.

Regarding these two variables, the gender factor in the first item, the male score higher than the female, this is in line with the results of previous observations. As for the impact of the professional category as a variable, the students in the liberal arts group have outstanding performance regardless of gender. The preservation rate of female students from the liberal arts group is even close to that of male students from medical group. It can be seen that the impact of the professional category is quite strong, and the impact on the results is no less than gender differences. The retention rate of Japanese vocabulary in Taiwanese Hokkien from the liberal arts group is higher than that of other majors. It should be that the students in liberal arts group who are more interested in language than other groups.

The preservation rate of Japanese vocabulary in Taiwanese Hokkien from comprehensive universities is better than the other two types. Why is there a difference in preservation rate among the comprehensive universities and universities of science and technology? Perhaps it is the result of the difference in humanities education between the two different types of universities.
This is due to the source of students for the comprehensive university differs from that for the university of science and technology. The students in the university are mainly from ordinary high schools, while the students in the university of science and technology are mostly from vocational schools. Therefore, these differences should have been generated by the student status at the time of admission. From this perspective, the student status, besides gender and professional category, at the time of admission also has an impact. In general, high school students should be consecutive high vocational students.

To sum up, gender, major category, and student status at the time of enrollment are three important variables that will have impacts on the decline of Japanese vocabulary in Taiwanese Hokkien among college students in Taichung.

\section{REFERENCES}

[1] J. K. Chambers, Peter Trudgill and Natalie Schilling-Estes (eds.), 2002, The handbook of language variation and change. Oxford and Malden, MA: Blackwell.

[2] W. Labov, Sociolinguistic patterns. Philadelphia, PA: University of Pennsylvania Press, 1972.

[3] Jungmin Li, "The analysis of the influence of socio-cultural changes on language use: in the example of the young people's use of Minnan dialect of in central Taiwan," The first International Conference on Chinese Dialect Culture, Kanazawa University, Japan, 2012.

[4] Jungmin Li, The practice of geographical linguistics, Taichung: Yiqiezhizhi Press, 2014.

[5] Douglas C. Montgomery and George C. Runger, Applied Statistics and Probability for Engineers, 4th edition, John Wiley, 2006. 